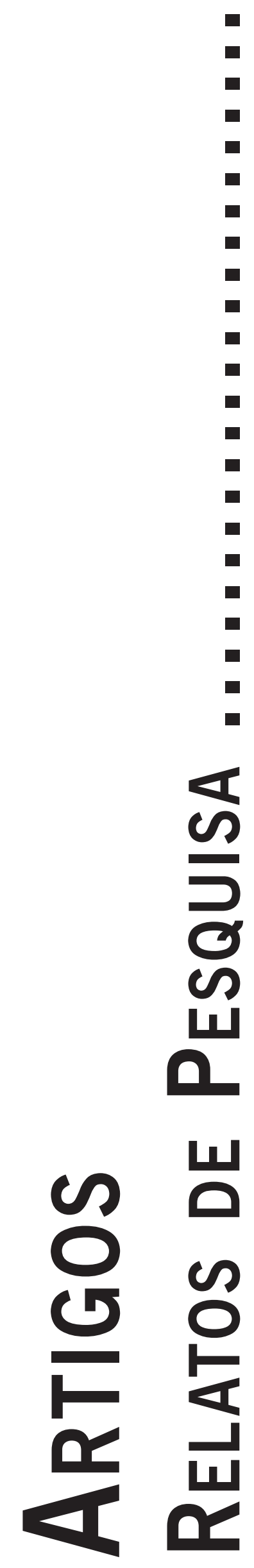




\title{
A ÉTICA DO CUIDADO E O ENCONTRO COM O OUTRO NO CONTEXTO DE UMA CLÍNICA-ESCOLA EM FORTALEZA
}

\author{
The Ethics of Care and the Meeting with the Other in a Context of a School Clinic in Fortaleza
}

La Ética Del Cuidado y el Encuentro con el Outro en el Contexto de una Clínica-Escuela en Fortaleza

\author{
Liliane Brandão Carvalho \\ Ana Maria Ferreira Alves \\ Clarissa Ale Passos \\ FERNANDA GOMES LOPES \\ Renata Bessa Holanda \\ VIRGINIA MOREIRA
}

\begin{abstract}
Resumo: O campo da psicologia clínica vivencia mudanças em seu saber, a partir de uma reconfiguração do modelo de clínica clássico, impulsionando transformações na formação do psicólogo. Indagamo-nos sobre como está ocorrendo a prática psicológica ainda na graduação. Considerando a psicologia como uma profissão da saúde, apropriamo-nos do conceito de cuidado para problematizar esta temática nas práticas psicológicas. Neste estudo, objetivamos compreender o cuidado como uma atitude ética na experiência vivida dos estagiários de psicologia, a partir de uma lente fenomenológica. Como recurso metodológico, utilizamos o método fenomenológico em uma perspectiva hermenêutica de influência gadameriana, tendo como instrumento a entrevista aberta com três perguntas norteadoras. Foram realizadas 10 entrevistas com estudantes em estágio clínico na clínica-escola no Serviço de Psicologia Aplicada SPA/NAMI da Universidade de Fortaleza. Emergiu como resultado a construção de uma rede interpretativa, a partir das falas dos informantes acerca de sua experiência vivida, possibilitando uma discussão sobre o cuidado. Concluímos que é importante, ainda na graduação, pensarmos acerca do cuidado na prática do psicólogo como possibilidade de acolhimento, respeito e afetação, como uma atitude ética para com o outro.
\end{abstract}

Palavras-chave: Cuidado; Pesquisa fenomenológica; Hermenêutica gadameriana; Formação em psicologia.

Abstract: The field of clinical psychology is going through changes in its knowledge, from a reconfiguration of the classic clinical model, driving changes in training of psychologists. We asked ourselves then how is occurring psychological practice still in graduation. With the inclusion of psychology in health area, we use the concept of care to discuss this issue in psychological practices. In this study, we aimed to understand the care, as an ethical attitude, in the experience of trainees in psychology from a phenomenological lens. As a methodological resource, we use the phenomenological method from a hermeneutic perspective of Gadamer's influence. We used as instrument the technique of open interviews with three guiding questions, totalizing 10 interviews with students on clinical practicum in the school clinic at the Serviço de Psicologia Aplicada SPA/NAMI Universidade de Fortaleza. Emerged as a result, a network of interpretive statements from the informants about their experience, enabling a discussion about care. We conclude that it is important, still in the graduation, think about the care in the practice of a psychologist as a possibility of host, respect and affectation, as an ethical attitude to each other.

Keywords: Care; Phenomenological research; Gadamer's hermeneutic; Psychology training.

Resumen: El campo de la psicología clínica experimenta cambios en su saber, a partir de una reconfiguración del modelo clínico clásico, impulsando transformaciones en la formación del psicólogo. Nos preguntamos cómo se está produciendo la práctica psicológica todavía en la graduación. Teniendo en cuenta la psicología como una profesión del área de la salud, nos apropiamos del concepto de cuidado para problematizar este tema en las prácticas psicológicas. En este estudio, tuvimos como objetivo comprender el cuidado como una actitud ética en la experiencia vivida por los pasantes de psicología, desde el punto de vista fenomenológico. Como recurso metodológico, fue utilizado el método fenomenológico en una perspectiva hermenéutica de influencia de gadameriana, utilizando como instrumento la entrevista abierta con tres preguntas orientadoras. Fueron realizadas diez entrevistas con estudiantes en prácticas clínicas en la clínica-escuela en el Servicio de Psicología Aplicada SPA/NAMI de la Universidad de Fortaleza. Surgió como resultado, llevando en cuenta el discurso de los informantes acerca de su experiencia, la construcción de una red interpretativa, lo que permite una discusión sobre el cuidado. Llegamos a la conclusión de que es importante, todavía en la graduación, pensar sobre el cuidado en la práctica del psicólogo como posibilidad de acogida, respeto, afectación y como una actitud ética hacia el otro.

Palabras clave: Cuidado; Investigación fenomenológica; Hermenéutica gadameriana; Formación en psicología. 


\section{Introdução}

As formações tradicionais dos cursos de graduação em psicologia têm priorizado as teorias sobre a subjetividade e o funcionamento psíquico do sujeito (Freire, 2003). Histórica e epistemologicamente, a psicologia foi permeada por uma práxis embasada no modelo biomédico que considerava o sujeito em sua patologia, isolado do âmbito social. Entretanto, a prática do psicólogo tem emergido com novas configurações, devido à necessária reflexão crítica e processual sobre este saber: o novo campo contextualiza o homem socialmente (Lo Bianco, Bastos, Nunes \& Silva, 1994).

A partir desta pertinente mudança, indagamo-nos a respeito de como está ocorrendo a formação do profissional de psicologia para trabalhar com as diversidades humanas na clínica. Haveria na prática do psicólogo um centramento nas teorias e técnicas em detrimento da relação de cuidado com o paciente? Diante dessa interrogação, buscamos investigar o cuidado na prática clínica do estagiário de psicologia numa clínica-escola de Fortaleza.

Entendendo a dimensão do cuidado enquanto uma atitude ética que acolhe o sofrimento do outro de forma integral (Ayres, 2007), corroboramos autores como Carvalho, Bosi e Freire (2008), os quais discorrem sobre o cuidado como pertencente à prática profissional do psicólogo. Percebemos a necessidade de pôr em questão esse tema ainda na fase da graduação quando os estudantes, nos momentos finais do curso de Psicologia, inserem-se no ambiente da clínica-escola. Cuidado este, bastante problematizado no campo da saúde e pouco no âmbito da psicologia (Carvalho, 2006). Entretanto, ao nos apoiarmos na inserção da psicologia na área da saúde (Brasil, 1997), buscamos refletir sob o espectro da psicologia neste campo a respeito da prática de cuidado realizada pelos psicólogos.

Enquanto dimensão ontológica, cuidado é originariamente compreendido como "cura” em Heidegger (1927/1997). O filósofo refere-se à cura como constituinte da existência humana: "Enquanto totalidade originária de sua estrutura, a cura se acha, do ponto de vista existencial a priori, 'antes' de toda 'atitude' e 'situação' da pre-sença, o que sempre significa dizer que ela se acha em toda atitude e situação de fato" (Heidegger, 1927/1997, p. 258).

Em seu estudo sobre o Ser, Heidegger (1927/1997) retoma a questão do sentido do Ser considerando este como o mais universal dos conceitos. O Dasein heideggeriano implica o ser-aí como local no qual o mundo se revela, como uma clareira de possibilidades que se abrem (Heidegger, 1964/2009).

Nesse sentido, Heidegger (1927/1997) considera o ser-aí como projeto, ou seja, incompleto, cuja completude só se dá na morte. Heidegger defende que somente quando tomamos consciência de nossa finitude, podemos alcançar uma existência autêntica e o contrário disso resultaria em uma existência inautêntica. Quanto à dimensão do cuidado, Heidegger revela-o como o ato de estar aberto às possibilidades, como uma disposição ao mundo, como um modo de ser que torna a existência do ser-aí autêntica.

Ayres (2004), de inspiração heideggeriana, entende o cuidado a partir de três categorias: ontológica, genealógica e crítica. A ontológica diz respeito ao cuidado como uma condição da existência humana, como o moldador da existência, o qual só concretiza-se a partir da mesma; e abrange aspectos constituintes da existência relevantes para a saúde, tais como o movimento, a interação, a identidade e alteridade, a plasticidade, o projeto, o desejo, a temporalidade, a não-causalidade e a responsabilidade. A genealógica implica uma compreensão histórica acerca da perspectiva das primeiras teorizações sobre o cuidado de si, na Grécia Antiga. O cuidado como categoria crítica refere-se ao modo de interação existente nas práticas de saúde contemporâneas, dedicando-se ao campo já delimitado da tecnologia e suas relações com o atendimento ao usuário. Cuidado é percebido como:

Um construto filosófico, uma categoria com a qual se quer designar simultaneamente, uma compreensão filosófica e uma atitude prática frente ao sentido que as ações de saúde adquirem nas diversas situações em que se reclama uma ação terapêutica, isto é, uma interação entre dois ou mais sujeitos visando o alívio de um sofrimento ou o alcance de um bem-estar, sempre mediada por saberes especificamente voltados para essa finalidade (Ayres, 2004, p. 74, grifos do autor).

O cuidado se encontra na raiz primeira do ser humano, é um modo-de-ser essencial, segundo Boff (1999), sendo uma dimensão sempre presente, irredutível, originária, ontológica e impossível de ser completamente desvirtuada: "Mitos antigos e pensadores contemporâneos dos mais profundos nos ensinam que a essência humana não se encontra tanto na inteligência, na liberdade ou na criatividade, mas basicamente no cuidado" (Boff, 1999, p. 11). O cuidado existe desde quando existe vida humana, ressaltam Coelho e Fonseca (2005) ao considerá-lo como atos de humanidade, através do qual a vida se mantém.

Compactuamos com Boff (1999) ao afirmar que "Cuidar é mais que um ato; é uma atitude. Portanto abrange mais que um momento de atenção, de zelo e desvelo. Representa uma atitude de ocupação, preocupação, de responsabilização e de envolvimento afetivo com o outro" (p. 33). O cuidado, nesta perspectiva, poderia ser estudado em aproximação à proposta da ética radical de Emmanuel Lévinas. Filósofo contemporâneo, ele vivenciou profundos desapontamentos nas I e II Guerras Mundiais no século XX, tendo ele mesmo sido um judeu prisioneiro de guerra. Propôs uma ética que se estrutura na relação inter-humana, na qual o Outro é a essência humana: “(...) o homem toma seu sentido maior na sua relação com o outro homem, com o próximo” (Pivatto, 2000, p. 81). 
Para Freire (2003), o sujeito é para o outro, sofre por seu sofrimento, responsabiliza-se pelo outro e pela sua responsabilidade, sendo esta a estrutura de nossa subjetividade. Ainda segundo Freire (2003), nós não somos e nem nascemos de determinada forma, mas somos esse anfitrião que ao receber o outro respondemo-lo a resposta originária em Lévinas (1961/1988), "eis-me aqui". Nesta, iremos hospedar sua alteridade que vem em excesso, sendo-nos impossível hospedá-lo em sua completude. Isso não indica haver nesta relação uma simples conformação acerca da alteridade trazida pelo outro, mas que aí haverá uma acolhida permeada pelo respeito e responsabilidade - no sentido de habilidade em responder - para com a alteridade (Lévinas, 1961/1988; Freire, 2003).

A partir de tais reflexões, consideramos importante resgatar a dimensão ética levinasiana por entendermos os atores envolvidos na práxis da saúde - como aqui focalizamos o lócus da clínica-escola - como sujeitos de responsabilidade pelo outro, que respondam ao seu apelo por acolhimento e cuidado. Neste estudo, demarcaremos cuidado para com o outro como uma preocupação com o seu projeto, aqui entendido como um constante devir, nunca completo ou fechado.

Em relação à clínica-escola, trata-se de um espaço no qual os graduandos põem em prática todo o conhecimento que adquirem no decorrer do curso, com a finalidade de ensino-aprendizagem, objetivando a capacitação do estudante para ser um profissional. Enquanto um lócus de possibilidades para a formação acadêmica, é também um espaço para reflexões críticas sobre as práticas psicológicas exercidas e os modos de estar a serviço do outro - o usuário (Oliveira-Monteiro \& Nunes, 2008). Ousamos também considerar a instituição como uma oportunidade para discutir e exercer o cuidado e a ética na prática clínica dos aspirantes a psicólogos.

Neste artigo, buscamos compreender o cuidado, como uma atitude ética, na experiência vivida dos estagiários de psicologia, em uma clínica-escola em Fortaleza/CE, a partir de uma lente fenomenológica.

\section{Procedimentos metodológicos}

Para a realização de nossa pesquisa utilizamos o método fenomenológico a partir de uma perspectiva hermenêutica de influência gadameriana. Por meio do método fenomenológico é possível acessar o significado da experiência vivida dos sujeitos.

A elucidação do vivido pela perspectiva da Fenomenologia Hermenêutica ocorre a partir da interpretação do pesquisador, importante à compreensão do fenômeno (Amatuzzi, 1996). Compreender "não é compreender melhor, nem saber mais, no sentido objetivo, em virtude de conceitos mais claros [...] Bastaria dizer que, quando se logra compreender, compreende-se de um modo diferente" (Gadamer, 1960/1997, p. 444).
A compreensão começa com a afetação ao diferente, condição hermenêutica primária e é iniciada a partir da suspensão dos preconceitos, que ocorrerá na estrutura da pergunta; a primazia da pergunta é estar disponível às possibilidades (Gadamer, 1960/1997). Quando interrogamos ao outro, disponibilizamo-nos à alteridade, às respostas que vierem, ou seja, às possíveis emergências dos significados do fenômeno.

A pesquisa fenomenológica em psicologia emergiu com a necessidade de estudar o que há de mais próprio do humano, a experiência vivida. O vivido é definido por Amatuzzi (2008) como aquilo que acontece anterior a reflexão, é a reação imediata, antes mesmo de conceituar sobre. Segundo Forghieri (1993), o significado da experiência vivida é apenas possível a partir do relato, o qual foi permitido pela utilização do método fenomenológico.

Com o intuito de compreendermos essa experiência vivida de cuidar para os estagiários em sua prática psicológica iniciante, utilizamos como instrumento a entrevista aberta com as seguintes perguntas disparadoras: Como é para você ser estagiário em clínica na clínica-escola? A partir desta sua prática em clínica na clínica-escola, como você define o cuidado? Você pode descrever uma situação vivenciada no estágio que exemplifique esse cuidado que você nos definiu?

A fase do estudo de campo foi realizada na clínica-escola no Serviço de Psicologia Aplicada SPA/NAMI Universidade de Fortaleza - no período de Outubro de 2010 a Junho de 2011. Definimos um planejamento para a execução do campo, através dos seguintes passos: 1) definição do critério de delimitação dos informantes: cursar a disciplina de Estágio em Clínica I, II ou III; 2) envio de um convite por e-mail aos professores-supervisores das disciplinas de estágio em clínica, solicitando a participação de seus alunos de estágio; 3) visita às supervisões dos estagiários, esclarecendo nossa pesquisa e convidando os alunos a participarem da mesma; e 4) realização das entrevistas, previamente agendadas, no campus da universidade, preferivelmente, no espaço da clínica-escola, após a leitura e assinatura do Termo de Consentimento Livre e Esclarecido por parte do estagiário. O projeto desta pesquisa foi submetido ao Comitê de Ética em Pesquisa COETICA - da Universidade de Fortaleza e obteve a aprovação, conforme parecer $n^{0}$ 218/2010.

No total, realizamos dez entrevistas, as quais foram gravadas e transcritas na íntegra por nós, pesquisadoras. Oportuno esclarecer que todos os nomes aqui atribuídos são fictícios e nossos informantes - alunos estagiários da clinica-escola entrevistados - receberam a denominação de: Argila, Alegoria, Cura, Higino, Júpiter, Rio, Saturno, Sorge, Tellus e Terra - em alusão à fábula do cuidado, criada por Higino e utilizada por Heidegger em Ser e Tempo (1927/1997) na sua discussão ontológica do Ser.

Como último passo, analisamos as entrevistas com vistas à construção de uma rede interpretativa. Primeiramente, a partir da leitura exaustiva das entre- 
vistas, categorizamos as falas que nos afetavam, ainda suspendendo nossos a prioris; percebendo a semelhança nas falas categorizadas, agrupamo-las em subdimensões que desvelaram as dimensões. Finalizando, identificamos dois grandes temas com a justaposição das dimensões como similaridade. Na rede interpretativa foram revelados dois temas: "ser estagiário" e "cuidado". Neste artigo focalizamos a discussão do "cuidado relacional", pertencente ao tema "cuidado".

\section{Resultados e discussão}

Na dimensão "Cuidado Relacional”, os informantes revelaram como consideram as relações de cuidado para com o outro e como a vivenciam. Discutiremos agora as subdimensões emergentes e mais significativas de acordo com o objetivo do nosso estudo.

Na primeira subdimensão, "acolhimento", os estagiários trataram de uma disponibilidade para escutar o outro, de recebê-lo no momento de seu sofrimento ou crise, estando realmente presente e construindo um ambiente que proporcione a livre expressão dos reais sentimentos dos sujeitos que procuram seus serviços e, a partir disto, construir vínculo terapêutico, tal como é desvelado nos trechos a seguir:

"o cuidado, o cuidado de receber esse cliente é... De acolher esse cliente no momento da crise dele” (Rio).

"o diferencial dessa acolhida é essa escuta, é você acolher um choro, é acolher na raiva, todos os sentimentos dele [...] Então acho que essa acolhida é muito importante nesse primeiro atendimento pra que ele se expresse mesmo de todas as formas, que se crie um vínculo, que ele perceba que ali ele vai ter um momento dele" (Argila).

Recorremos à Ayres (2004), quando afirma que o acolhimento acontece quando o profissional escuta o paciente, ou seja, o outro, considerando que o profissional de saúde, como o psicólogo ou o psicólogo em formação, tal como privilegiamos neste estudo, deve buscar a escuta existencial do sujeito:

É preciso dispor a escuta para esse outro de forma a poder responder a ele, ao seu sofrimento (nudez e miséria em Lévinas). Essa resposta é responsabilidade: responsabilidade pelo outro, pelo seu sofrimento, por sua angústia. Estar a serviço do outro, portanto, é o que se espera de quem trabalha em um serviço de psicologia. (Freire, 2003, p. 14, grifo do autor)

“Cuidado é relação interpessoal”, ressaltam Pinheiro e Guizardi (2004, p. 37) ao evocarem os profissionais de saúde à reflexão de suas ações, as quais devem se afas- tar da referência de simples intervenção para se aproximar de uma verdadeira noção de cuidado. Ações como tratar, respeitar, acolher e atender o ser humano em seu sofrimento são essenciais para uma real atitude de cuidado para com o outro.

De forma correlacionada, os estagiários trouxeram também o "Respeito para com o Paciente" como algo necessário para o bom andamento do processo terapêutico. Neste, é preciso realizar um acompanhamento respeitoso que considera os limites de cada paciente, sem assumir uma postura diretiva, tal como revelam os seguintes excertos:

"É saber a hora certa, de trabalhar cada tema, cada assunto, cada relação. Porque os pacientes têm tempos diferentes. E cada relação dele tem um tempo pra ser trabalhada. E eles vão aos poucos também” (Cura).

"Você ter cuidado com as intervenções, respeitar o tempo dele, porque isso vai, querendo ou não, se a pessoa tá ali no processo [...] O que ela tá querendo chegar, em um ponto, você não precisa forçar esse ponto com o paciente" (Júpiter).

Nossos informantes ressaltam que o trabalho do psicólogo deve ser o de facilitar o processo do cliente, e não somente assumir uma postura de detentor do saber, como aquele que dá respostas prontas e convoca o sujeito a tomar atitudes embasadas em condutas de julgamento moral, sem uma perspectiva crítica própria. Os informantes enfatizam a importância da implicação do sujeito em seu processo psicoterapêutico, sendo ele quem demarcará o caminho a ser seguido:

“O cuidado em relação aos pacientes seria mais nesse sentido [...] Refletindo mais essas questões junto com ele, nunca dando nada pronto pra ele, nunca dando instruções, [...] Fazer esse cliente refletir sobre o lugar que ele tá se posicionando, né? Frente a algumas situações, pra que ele mesmo chegue nesse caminho pra ser percorrido" (Saturno).

"[...] é fazer ele pensar sobre e fazendo ele pensar sobre, faz com que ele elabore e melhore, e é o que é, é o que tá acontecendo com ele, então é esse cuidado" (Terra).

"A partir do momento que você se coloca não como uma pessoa que tem um saber a mais que ele, mas como uma pessoa que tá ali pra escutar ele, pra ser um agente facilitador pra que ele crie esses recursos, e que ele possa criar alternativas criativas pra que ele possa passar aquela crise da melhor forma possível” (Argila).

De acordo com Freire (2003), o serviço de psicologia aparece como um atendimento destinado ao outro, no qual o profissional deve disponibilizar a escuta 
para o paciente, deve responder a ele, ao seu sofrimento. Compreendemos que para atingir essa escuta do outro é necessário exercer o ato de cuidar. É impossível cuidar sem expor-se ao outro, sem aceitar o outro como ele é: "Será necessária a abertura aos encontros de afecção, será necessário encontrar-se com o outro. A exclusão da alteridade é a exclusão do cuidado" (Ceccim \& Palombini, 2009, p. 310).

Freire (2003) vai além dessa dimensão da admissão da alteridade do outro no atendimento psicológico ao enfatizar a perspectiva do profissional propiciar ao paciente uma descoberta do seu outro, seu estranho, indo de encontro às ideias preconizadas em psicologia de reafirmar a identidade do sujeito. Afirma ser necessário uma revisão das teorias psicológicas para possibilitar uma prática renovada, propiciando o surgimento impertinente do outro, nas falas e nos gestos do paciente:

É assim que, em nossa forma de ver, é possível falar-se de Ética e de democracia nos serviços de psicologia. Estar a serviço do outro que nos procura para poder assisti-lo em seu devir-outro e escutar sua alteridade, principalmente naquilo que o fará buscar qualidade de vida para si e para os outros (Freire, 2003, p. 14).

A temática ética mostrou-se nos depoimentos dos informantes como uma questão primeira para a construção da relação de cuidado para com o sujeito, relação na qual o sigilo, próprio da profissão do psicólogo, deve ser assegurado, tal como foi revelado nos excertos abaixo:

"Ser ético é você ter responsabilidade naquilo que você vai dizer, porque nós somos responsáveis por aquilo que falamos, né? Então é você estudar pra você ter responsabilidade naquilo que você vai dizer, pra mim isso é ética também. [...] Você tem que ser muito pontual naquilo que você vai dizer, você querer o melhor pro outro" (Tellus).

"Eu não posso chegar lá e impor uma coisa que é minha, tem que tentar ser o mais neutro possível” (Cura).

"Não interessa se você é psicanalista, se você gosta de uma abordagem de Psicanálise, se você tá com a Gestalt, com Comportamental, não interessa. Eu acho que você tem que ver um cuidado com o outro, uma questão ética” (Sorge).

Porém, aqui ressaltamos que mesmo trazendo à tona a questão da ética, os estagiários entrevistados revelaram em alguns momentos diminuta clareza sobre essa questão enquanto uma atitude de cuidado para com o outro, entendendo-a estreitamente relacionada a facetas de suas rotinas ou somente como o sigilo ético da profissão, como podemos perceber a seguir:
"Então eu acho também a questão da ética, o que você ouviu ali, ali vai ficar, você assegurar isso pro seu paciente, isso pra mim também é um cuidado" (Sorge).

“[Ética] é o máximo de cuidado, tanto com o próprio paciente, pra não vazar nenhuma informação" (Cura).

"Essa questão do ônibus que... Realmente pra mim, seria uma coisa, falta de ética, não sei nem se seria ética, falta de ética, eu sentar do lado, eu sei que ela ia puxar assunto, e que eu iria conversar, [...] por um acaso ela subiu numa parada antes que a minha e por um acaso a gente se encontrou no ônibus" (Rio).

Uma perspectiva ética não significa necessariamente o seguimento de regras, modelos ou teorias, mas, sim, o desenvolvimento de sensibilidade para superar dilemas, com os quais estaremos sempre envolvidos de alguma forma (Souza, Souza \& Souza, 2005). Ética é responsabilidade pelo outro e por seu sofrimento, afirma Lévinas (1961/1988) ao articular uma ética em que se deve estar a serviço de Outrem, sendo esta relação entre o eu e o outro essencial, na qual implica a formação e instauração da subjetividade, e sendo também o momento em que se entra em contato com a alteridade trazida por outro para mim, sem podermos recusar tal responsabilidade. Para termos uma verdadeira relação ética com o outro, temos que encará-lo como alguém que traz consigo a diferença, considerada um fim em si mesmo (Lévinas, 1961/1988).

Em outra subdimensão, nomeada de "Promoção de Fala e Escuta”, os informantes abordaram a importância de se construir um espaço possibilitador da fala autêntica dos sujeitos, na qual a escuta toma lugar primordial. Essa escuta deve ser especializada, não podendo ser restrita apenas ao ouvir habitual, rotineiro, mas uma ação interessada, atenta, que considera o sujeito em sua forma integral:

"Todo mundo precisa sentir que tem alguém interessado em pelo menos ouvir, pelo menos entender, não dizer que a pessoa tem razão, [...] mas pelo menos dizer: 'Nesse espaço aqui você pode falar sobre o que você sente, independente se for certo, se for errado"” (Tellus).

"E de você, naquele momento, tá ali pra escutá-lo. [...] Olhar, o ouvir, o ouvir mesmo, não tá ali sentado e tá com a cabeça não sei aonde" (Sorge).

Quando revelaram a "Promoção de Saúde e Bemestar”, os estagiários definiram o que seria promover saúde e qual o lugar necessário para realizar tal ação, entrelaçando tal temática com uma atitude de cuidado, tal como é denotado nos trechos seguintes: 
"De gerar saúde mental, de gerar saúde emocional, de... diminuir a tensão da família. Então tudo isso é cuidado" (Tellus).

"Ser promotor de saúde é tentar promover o bem estar do sujeito e potencializar os aspectos positivos que ele tem, para além da doença [...] acho que enquanto promotor de saúde, a gente também tem que ter um olhar do sujeito em sua totalidade, do sujeito de uma forma íntegra" (Alegoria).

É importante ressaltarmos que, mesmo desempenhando esse papel de promotor do cuidado, as instituições de saúde devem estar sempre atentas ao tipo de cuidado disponibilizado ao usuário do serviço, pois

(...) historicamente, o campo da saúde tem sido marcado por intervenções balizadas por um certo exercício do poder-saber técnico, cujo principal efeito - e, ao mesmo tempo, premissa de sua viabilidade - pode ser identificado na produção de um outro objeto de intervenção, e não sujeito de relação. Um outro (comunidade, 'paciente' família etc.) desprovido de singularidade, desejo, saber e história. Em suma, um encontro que se tem concretizado mediante a referência da normalização que marca o exercício do poder disciplinar que configurou e determinou as relações sociais na modernidade (Pinheiro \& Guizardi, 2004, p. 37-38).

Entendemos haver um necessário processo de desconstrução no campo da saúde, afetando as práticas rotineiras dos profissionais da saúde, a partir da discussão sobre a dimensão relacionada à maior interação interpessoal e à ideia do cuidado integral. Para Ayres (2004), o cuidado adentra essa discussão como uma possibilidade de inserir-se no arcabouço teórico e filosófico constituinte da reconfiguração do campo da saúde.

Segundo os informantes deste estudo, o terapeuta será quem deve dar ênfase a este outro no momento da terapia, colocando em suspenso seus a prioris e questões próprias para tornar possível uma escuta especializada, considerando os sentimentos, sensações, pensamentos, atitudes daquele que sofre:

"Eu acho que sou eu sair de cena pra ele entrar em cena. Eu acho que naquele momento é o paciente" (Sorge).

"E a nossa proposta, enquanto profissional é dar conta do outro. Então a gente precisa exercitar esse cuidado, esse dar conta do outro" (Tellus).

Por conseguinte, para termos um trabalho pautado no cuidado para com o outro, entendemo-lo em estreita relação com uma atitude ética. Corroboramos Boff (2003) ao ressaltar o cuidado como uma atitude de ética mínima e universal, chegando a ter um poder de prolongar a duração e melhorar a condição de vida de um ser cuidado.

Os estagiários revelaram a questão da "Presença" como algo significativo ao considerá-la não se tratar apenas em estar ao lado do sujeito, fisicamente, mas também, de acompanhá-lo em suas trajetórias de vida, sendo um sujeito ativo juntamente ao outro em seu processo psicoterapêutico:

"Porque tem dia que [...] você precisa tá numa consulta, tem prova, você tem 'n' coisas pra fazer, você tá com uma cabeça a mil [...] se tiver um tempo ainda favorável, às vezes, eu acho melhor cancelar, porque se você não tiver ali presente, porque aquele tempo ali, aquele 50 minutos é dele” (Rio).

"Mostrar que tá ali como pessoa, que tá ali do lado dele" (Cura).

"[o cuidado é] O momento de tá com a pessoa (...)" (Sorge).

Os depoimentos ainda desvelaram a questão da "Totalidade", na qual os estagiários trouxeram questões próprias da constituição dos sujeitos - seja em termos pessoais, profissionais, sociais, familiares - e tomavam-nas como pontos-chave na real compreensão e escuta diferenciada destes:

"O cuidado, acho que é um olhar integral ao sujeito, enxergar o sujeito em sua totalidade” (Higino).

“[deve ser considerado] com o todo. Porque, assim, o que é que o Psicodrama diz? O Psicodrama diz que o homem é um ser de relações. [...] E as relações não são somente pessoais. Eu me relaciono com objetos, com locais..." (Cura).

"então é importante também você tá investigando as outras, por exemplo, quando é criança você não pode trabalhar só com a criança, se ela vem encaminhada do colégio você esteja em contato com o colégio, você esteja em contato com os pais" (Argila).

Tais depoimentos denunciam não ser possível cuidar de uma doença ou de um problema de forma isolada e específica, desconsiderando as influências e variáveis às quais um sujeito está submetido, bem como a dinâmica de vida que o envolve. A maior preocupação que devemos ter se refere à imprescindibilidade da atenção às reais necessidades dos pacientes para além de cuidados tecnológicos ou que demandem exclusivamente fins de cura (Souza, Souza \& Souza, 2005).

Tanto Santos e Shiratori (2005) como Zeferino e cols. (2008) levantam a necessidade do trabalho com as pessoas 
de maneira holística, considerando cada paciente como um ser singular. Consideram, também, essencial um trabalho pautado nas habilidades de ouvir, ver, sentir e compreender os pacientes, sendo possível perceber, de forma mais aproximada, as necessidades expressas por eles.

Questões referentes ao se colocar no lugar do outro foram agrupadas na subdimensão "Empatia”, na qual os estagiários tratam da importância de se estar em constante exercício de afetação diante daquilo trazido pelo outro, como constatamos nos tópicos a seguir:

"Mas assim, muitas coisas que quando eu vou deixá-lo fora [da sala], quando eu vou transcrever, muitas coisas vêm e eu fico: 'Poxa vida! Como é que essa pessoa tá suportando tanto sofrimento? Como é sofrido pra ela isso!'”(Sorge).

"Cuidado é tentar... é sentir como é que ele tá. Tentar se colocar no lugar dele” (Cura).

"Eu acho que sempre passar pela experiência de tá se posicionando no lugar de cliente já é muita coisa... Assim, já é uma experiência” (Saturno).

Luz (2004) explicita o âmbito da saúde como o lugar de relações de empatia, entendendo o cuidado como o respeitar, o atender, o acolher o ser humano em seu sofrimento. Percebemos nessa definição uma concordância com a delimitação do ato de cuidar em Corbani, Brêtas e Matheus (2009, p. 350):

Usar da própria humanidade para assistir a do outro - como ser único, composto de corpo, de mente, vontade e emoção, com um coração consciente, que com seu espírito intui e comunga. Falamos, portanto, de seres pensantes, dotados de dignidade, a ser cuidados em sua totalidade. A recíproca é verdadeira, quando o outro em sua humanidade cuida da minha. Logo, o cuidado está apoiado numa relação inter-humana.

Transpondo as perspectivas somente técnicas ou teóricas, os informantes abordam também a importância da construção de vínculos de confiança no processo psicoterapêutico por meio do cuidado, da atenção e do acolhimento, considerados essenciais para um bom andamento do processo. Explicitam uma relação entre duas pessoas como uma "via de mão dupla", na qual os dois sujeitos que constituem o setting terapêutico - terapeuta e usuário - se implicam e afetam-se mutuamente, tal como desvelam os excertos seguintes:

"Assim, acho que no momento em que você pega o paciente, que você já tá em clínica 1, que você assina o termo de compromisso, tem que começar os cuidados com essa pessoa" (Sorge).
"Tem que ver se naquele dia ela tá aberta pra isso, se não vai machucar muito naquele dia, porque pra trabalhar qualquer relação, qualquer coisa precisa também ter essa abertura com o paciente. E eu acho que é esse o cuidado que a gente tem" (Cura).

“[...] porque o psicólogo vai muito na parte técnica, estabelecer rapport, mas o que é estabelecer rapport? É você tá ali no vínculo, [...] tem que esquecer a parte mecânica sabe, [...] mas pra mim é uma coisa que acontece naturalmente, essa relação com outra pessoa" (Terra).

"que muitas vezes é difícil criar esse vínculo que as pessoas já chegam aqui, por mais que elas venham procurar por demanda delas, mas elas chegam com receio, falar com uma pessoa que elas nunca viram, que elas não confiam, então assim eu acho que essa acolhida é um ponto muito importante pra que se crie esse vínculo com o paciente e pra que eles saiam daqui bem mais aliviados" (Argila).

Em Boff (1999), o cuidado se encontra na raiz primeira do ser humano, antes mesmo deste fazer qualquer coisa e, caso o faça, sua ação sempre vem acompanhada e imbuída de cuidado. Para este autor, cuidado é um modo-de-ser essencial, sendo uma dimensão sempre presente, irredutível, originária, ontológica e impossível de ser completamente desvirtuada.

Quanto ao cuidado para com o outro, os informantes deste estudo revelaram-no de modo relacionado às intervenções e suas práticas, as quais devem ser devidamente embasadas na experiência teórica e prática. Aqui aparecem falas mais voltadas às perspectivas técnicas, algumas vezes burocráticas, levantando a importância do cuidado com cada intervenção realizada:

"De saber realmente que pode atuar com esse paciente, como é que ele vai reagir a determinadas falas suas, a determinadas intervenções que vocêfaz, ou a determinadas propostas que vocês façam” (Saturno).

"tem que cuidar com as palavras, com o que você vai mexer com o paciente, se vai cutucar uma coisa, se você vai cutucar aquela coisa, tem que fechar, não adianta você cutucar uma ferida e deixar aberta né” (Argila).

"E dentro da própria sessão fazer troca de papéis [...] Incorporo gestos, a maneira de falar, de sentar, e ás vezes, incorporado, também perceber como é que ele tá, como é que esse paciente tá se vendo. [...] A gente vai utilizar das técnicas do próprio Psicodrama” (Cura).

Refletimos, então, nesse espectro da psicologia no campo da saúde a respeito da prática do cuidado realizada 
pelos psicólogos. No entanto, devemos aqui admitir que a prática dos psicólogos ainda centra-se mais em teorias sobre a subjetividade e, como uma profissão da saúde, embasa-se na clínica tradicional ou no próprio modelo biomédico (Carvalho, Bosi \& Freire, 2008).

Este modelo, também denominado como modelo mecanicista, teve suas raízes no Renascimento, mais especificamente no racionalismo. Este pensamento acabou por dominar as práticas médicas, que passaram a se deter ao viés explicativo, sendo o lugar de maior importância conferido a uma perspectiva nosográfica, lugar antes ocupado por uma descrição biográfica das doenças (Barros, 2002). Mesmo que este modelo tenha possibilitado descobertas importantes para o tratamento e cura de doenças, ao longo dos anos passou a ser problematizado por focar-se em uma ordem reducionista: a doença era considerada a principal meta dos profissionais médicos, em detrimento do histórico de vida e adoecimento do sujeito. Essa postura reflete na formação dos futuros psicólogos, que veem nas clínicas-escolas a possibilidade de exercerem seus primeiros ensaios profissionais.

Estudos sobre o funcionamento dos serviços de psicologia na clínica-escola, apontados por Barbosa (1992) e Campezatto e Nunes (2007), demonstram que os estagiários estavam apenas transpondo técnicas aprendidas na formação, em sua maioria, descontextualizando o sujeito de sua comunidade. Compreendemos que para haver um atendimento efetivo e humanizado, faz-se presente a atitude do cuidado, enquanto uma dimensão ética, e do acolhimento do sujeito em sua integralidade. Para Carvalho (2006), escolher não centrar na patologia, mas cuidar do sujeito em sua alteridade é, acima de tudo, uma escolha ética.

Enfatizamos a necessidade do estagiário não criar uma relação de mera objetivação para com o paciente e sim facilitar uma relação de intersubjetividade (Ayres, 2004). Consideramos importante o estagiário não reduzir seu atendimento aos conhecimentos científicos, utilizando-se também do juízo prático (Ayres, 2004), para compreender qual intervenção deverá realizar, disponibilizando-se de toda a sua sabedoria, para facilitar o processo terapêutico, respeitando a alteridade do paciente. Processo este que parte da premissa que o sofrimento e o adoecimento estão associados ao entendimento do processo de saúde-doença, cuja compreensão implica o respeito à percepção do próprio sujeito do seu adoecer para além dos fatores biológicos, privilegiando a sua inserção no ambiente como constituintes das condições gerais de saúde (Lacerda \& Valla, 2004). A partir do trecho de um entrevistado, a experiência de cuidado na clínica-escola é desvelada como:

"Você não vai dizer tudo o que a pessoa tem que fazer, mas você vai dar um suporte no descobrir desse 'o que é nossa família?', 'o que é que a gente tem pra melhorar?', 'o que é que a gente tem pra mudar?', 'por que é que a gente age dessa forma?'. [cuidado pra mim] é estar lá, dando suporte pra que essa família se descubra enquanto família, enquanto sistema, enquanto funcionamento" (Tellus).

Percebemos, a partir dessa fala que muitas vezes o paciente não tem ferramentas para perceber-se e aceitarse como incompleto, ou, nas palavras do próprio informante, "em funcionamento", e que esse processo depende também de uma atitude do terapeuta em entendê-lo como tal. Outro estagiário expõe como deve ser a posição do terapeuta que se preocupa com o projeto do paciente:

"Andante, andar junto com o psicótico, porque o psicótico tem essa coisa desorganizada e o analista não tem que ficar querendo organizar essa desorganização. Ele tem que administrar um pouco essa bagunça, mas não colocar em ordem, porque o delírio, essas alucinações, seja o que for, é uma maneira de ele se estruturar, então eu não tenho que tirar isso dele” (Sorge).

Com isso, podemos entender que o terapeuta não deve ter o paciente como mero objeto de intervenção, e sim como um constante devir que demarca um projeto, o qual não deve ser meramente enquadrado em um diagnóstico ou em um tratamento pré-determinado.

Na outra extremidade, a posição do terapeuta também não deve consistir em reafirmar uma identidade própria do sujeito, mas propiciar ao paciente uma descoberta do seu outro, que lhe é estranho (Freire, 2003). Enquanto uma atitude ética, consideramos que, diante do usuário do nosso serviço, devemos vê-lo como sujeito, sendo fundamental ter para com ele uma relação de afetação e cuidado, marcadamente uma relação sujeito-sujeito, cuja base precisa conter aceitação e acolhimento, sem que com isso nos descolemos dos conhecimentos objetivos em relação aos distintos processos de adoecimento e sofrimento humano.

\section{Considerações finais}

Através do contato com alunos do curso de graduação em psicologia, pudemos discutir a temática do cuidado para melhor compreendermos como este vem sendo entendido, definido e experienciado por estes futuros profissionais.

A clínica-escola foi escolhida como campo de estudo por se caracterizar, de acordo com Campezzato e Nunes (2007), como um espaço de desenvolvimento pessoal e profissional, onde deve ser questionada a atuação de futuros profissionais cuidadores da saúde. A utilização deste espaço pelos estagiários, realmente, parece marcada por um sentido reflexivo, que os convoca a uma postura mais crítica e questionadora, sendo esta uma postura necessária para o (próximo) profissional psicólogo. 
Os informantes desta pesquisa compreendem a clínica-escola como um local de contato com o exercício profissional, fundamental para o seu desenvolvimento por ser um espaço que permite a experimentação, além da reflexão crítica.

Entendemos que o cuidado está para além das técnicas ou práticas burocráticas, ou mesmo de atitudes que pregam um sentido do mero acolher, sem que aí haja uma verdadeira afetação e responsabilidade do profissional para com o usuário. Dessa forma, o cuidado é compreendido como uma dimensão filosófica, um construto estabelecido na relação intersubjetiva, embasado em uma atitude que visa acolher e respeitar o sofrimento do outro mediante utilização de saberes práticos e experienciais.

Os sujeitos entrevistados revelam, em diversos momentos, sua atuação como uma prática cuidadora, ressaltando uma atitude de afetação para com aquele outro que lhes chega, mostrando preocupação em aliviar seu sofrimento, assumindo uma postura acolhedora. Contudo, com a influência do modelo biomédico vigente, retratam por vezes, atitudes que priorizam as técnicas, as regras institucionais, a preocupação com as obrigações burocráticas em detrimento de uma relação interpessoal cuidadora.

Compreendemos a importância da técnica para atuação do profissional de saúde, contudo, acreditamos ser necessária a constante indagação do seu exercício. Assim, o psicólogo, como profissional que compreende o sujeito em sua totalidade, integralidade e complexidade, vê-se diante de uma atuação que exige constantes indagações e atitudes críticas, desde os primeiros ensaios profissionais - tais como aqueles vivenciados em uma clínica-escola. Como vimos, a graduação ainda tende a priorizar as teorias da subjetividade, o que torna fundamental um posicionamento crítico frente às práticas psicológicas existentes, a partir de uma dimensão ética do cuidado.

Mesmo que identifiquemos que os estagiários tomem, em muitos momentos, um rumo mais próximo de um trabalho pautado no cuidado para com o outro, vale a pena destacar a necessidade de maiores discussões. A teoria que define o cuidado é clara quando afirma que este deve ser uma atitude ética para com o outro, acolhendo-o em sua alteridade e em todo seu sofrimento. No entanto, quando este é exercido na prática, percebemos que muitas atitudes ainda carecem de um real embasamento na responsabilidade, na afetação, na relação interpessoal e no trabalho compromissado. Um verdadeiro entendimento - não somente teórico como também prático - deve ser investido e incentivado tanto para aqueles em formação como para aqueles que formam, sendo necessária a revisitação de algumas práticas exercidas de forma já naturalizada, ou seja, certas atitudes influenciadas pelo tecnicismo vigente nas instituições de saúde.

\section{Referências}

Amatuzzi, M. M. (1996). Apontamentos acerca da pesquisa fenomenológica. Estudo de Psicologia, Campinas, 13(1), 1-10.

Amatuzzi, M. M. (2008). Por uma psicologia humana (2. ed.). Campinas: Alínea.

Ayres, J. R. C. M. (2004, setembro). Cuidado e reconstrução das práticas de Saúde. Interface - Comunicação, Saúde, Educação, Botucatu, 8(14), 73-92.

Ayres, J. R. C. M. (2007). Da necessidade de uma prática reflexiva sobre o cuidado: a hermenêutica como acesso ao sentido das práticas de saúde. Em R. Pinheiro \& R. Araújo (Orgs.), Razões públicas para a integralidade em saúde: o cuidado como valor (p. 127-144). Rio de Janeiro: Editora do Centro de Estudos e Pesquisas em Saúde Coletiva.

Barbosa, J. I. C. (1992). Uma caracterização preliminar das clínicas-escola de Fortaleza (Dissertação de Mestrado em Psicologia Clínica). Universidade de São Paulo, São Paulo.

Barros, J. A. C. (2002). Pensando o Processo Saúde Doença: a que Responde o Modelo Biomédico? Saúde e Sociedade, 11(1), 67-84.

Boff, L. (1999). Saber Cuidar: Ética do humano - compaixão pela terra. Petrópolis, RJ: Vozes.

Boff, L. (2003). Ética e moral: a busca dos fundamentos. Petrópolis, RJ: Vozes.

Brasil (1997). Conselho Nacional de Saúde. Ministério da Saúde. Resolução no 218, de 06 de março de 1997. Reconhece os profissionais de nível superior de saúde. Disponível em: <http://www.datasus.gov.br/conselho/resol97/res21897. htm.> Acesso em: $07 \mathrm{dez} 2010$.

Campezatto, P. M., \& Nunes, M. L. T. (2007). Atendimento em clínicas-escola de psicologia da região de metropolitana de Porto Alegre. Estudos de Psicologia, 24(3), 363-374, jul. 2007.

Carvalho, L. B. (2006). Práticas do psicólogo em instituições públicas de saúde [manuscrito]: o cuidado para com o outro (Dissertação de Mestrado). Universidade Federal do Ceará, Fortaleza.

Carvalho, L., Bosi, M., \& Freire, J. (2008). Dimensão ética do cuidado em saúde mental na rede pública de serviços. Revista Saúde Pública, 42(4), 700-706, mar. 2008.

Ceccim, R. B., \& Palombini, A. L. (2009). Imagens da infância, devir-criança e uma formulação à educação do cuidado. Psicologia \& Sociedade, Florianópolis, 21(3), 301-312, set.-dez./2009.

Coelho, E. de A. C., \& Fonseca, R. M. G. S. da. (2005). Pensando o cuidado na relação dialética entre sujeitos sociais. Revista Brasileira de Enfermagem, 58(2), 214-217.

Corbani, N. M. S., Brêtas, A. C. P., \& Matheus, M. C. C. (2009). Humanização do cuidado de enfermagem: o que é isso? Revista Brasileira de Enfermagem, Brasília, 62(3), 349-354, maio-jun/2009. 
Forghieri, Y. C. (1993). Psicologia fenomenológica: fundamentos, método e pesquisas. São Paulo: Pioneira.

Freire, J. C. (2003). A Psicologia a Serviço do Outro: Ética e Cidadania na Prática Psicológica. Psicologia, Ciência e Profissão, Brasília, 23(4), 12-15.

Gadamer, H-G. (1997). Verdade e Método. Petrópolis: Vozes (Original publicado em 1960).

Heidegger, M. (1997). Ser e Tempo (6. ed.). Petrópolis: Vozes (Original publicado em 1927).

Heidegger, M. (2009). Seminários de Zollikon. Petrópolis: Vozes/ EDUC/ABD (Original publicado em 1964).

Lacerda, A., \& Valla, V. V. (2004). As Práticas Terapêuticas de Cuidado Integral à Saúde como Proposta para Aliviar o Sofrimento. Em R. Pinheiro \& R. A. de Mattos (Orgs.), Cuidado: as Fronteiras da Integralidade (p. 91-101). Rio de Janeiro: Hucitec ABRASCO.

Lévinas, E. (1988). Totalidade e infinito. Lisboa: Edições 70 (Original publicado em 1961).

Lo Bianco, A. C., Bastos, A. V., Nunes, M. L., \& Silva, R. C. (1994). Concepções e atividades emergentes na psicologia clínica: implicações para a formação. Em Conselho Federal de Psicologia, Psicólogo brasileiro: Práticas emergentes e desafios para a formação (p. 7-79). São Paulo: Casa do Psicólogo.

Luz, M. T. (2004). Fragilidade Social e Busca de Cuidado na Sociedade Civil de Hoje. Em R. Pinheiro \& R. A de Mattos (Orgs.), Cuidado: as fronteiras da integralidade. Rio de Janeiro: CEPESC/UERJ, ABRASCO.

Oliveira-Monteiro, N. R., \& Nunes, M. L. T. (2008). Supervisor de psicologia clínica: um professor idealizado? Psico-USF, 13(2), 31-43, dez. 2008.

Pinheiro, R., \& Guizardi, F. L. (2004). Cuidado e Integralidade: por uma genealogia de saberes e práticas no cotidiano. Em R. Pinheiro \& R. A de Mattos (Orgs.), Cuidado: as fronteiras da integralidade. Rio de Janeiro: CEPESC/UERJ, ABRASCO.

Pivatto, S. (2000). Ética da alteridade. Em M. Oliveira (Org.), Correntes fundamentais da ética contemporânea. Petrópolis: Vozes.

Santos, C. C. V., \& Shiratori, K. (2005). A influência da comunicação não verbal no cuidado de enfermagem. Revista Brasileira de Enfermagem, 58(4), 434-437, jul-ago

Souza, L. B. de, Souza, L. E. E. M. de, \& Souza, A. M. A. (2005). A ética no cuidado durante o processo de morrer: relato de experiência. Revista Brasileira de Enfermagem, 58(6), 731734, nov-dez.

Zeferino, M. T., Santos, V. E. P., Wall, M. L., Rocha, P. K., Blois, J. M., \& Meireles, B. H. S. (2008). Concepção de Cuidado na visão de Doutorandas de Enfermagem. Revista Enfermagem UERJ, Rio de Janeiro, 16(3), 345-350, jul-set.
Liliane Brandão Carvalho - Docente do curso de Graduação em Psicologia da Unifor (Universidade de Fortaleza), Doutora em Saúde Coletiva pela UFC/UECE/UNIFOR e Pesquisadora do Laboratório APHETO/UNIFOR. Endereço Institucional: APHETO - Laboratório de Psicopatologia e Psicoterapia Humanista Fenomenológica Crítica. Universidade de Fortaleza. Avenida Washington Soares, $n^{\circ} 1321$, Edson Queiroz. CEP: 60811-905, Fortaleza, Ceará, Brasil.

E-mail: liliane@unifor.br

Ana Maria Ferreira Alves - Psicóloga pela Unifor (Universidade de Fortaleza) e Pesquisadora do Laboratório APHETO/UNIFOR.

E-mail: anamariaferreiralves@gmail.com

Clarissa Ale Passos - Graduanda em Psicologia pela Unifor (Universidade de Fortaleza), Bolsista FEQ/UNIFOR e Pesquisadora do laboratório APHETO/UNIFOR.

E-mail: clarissaale@terra.com.br

Fernanda Gomes Lopes - Psicóloga e Pesquisadora do Laboratório APHETO/UNIFOR.

E-mail:nandinhagl@hotmail.com

Renata Bessa Holanda - Psicóloga pela Unifor (Universidade de Fortaleza) e Pesquisadora do Laboratório APHETO/UNIFOR.

E-mail: renatabessa_h@hotmail.com

Virginia Moreira - Pós-Doutora em Antropologia Médica (Harvard Medical School), Professora Titular do Programa de Mestrado em Psicologia da Universidade de Fortaleza - UNIFOR e Coordenadora do Laboratório APHETO/UNIFOR.

E-mail: virginiamoreira@unifor.br

Recebido em 05.05.2013 Primeira Decisão Editorial em 05.08.2013 Segunda Decisão Editorial em 20.09.2013 Aceito em 20.06.2014 